\title{
Role of positive glucose challenge test only versus oral glucose tolerance test in pregnancy outcome: a comparative study
}

\author{
Neha Homagai ${ }^{1}$, Nirajan Mainali², Sikha Rijal ${ }^{3}$ \\ ${ }^{I}$ Department of Obstetrics and Gynecology, Nobel medical college teaching hospital, Biratnagar, Nepal \\ ${ }^{2}$ Department of Pathology, Nobel medical college teaching hospital, Biratnagar, Nepal \\ ${ }^{3}$ Department of Biochemistry, Nobel medical college teaching hospital, Biratnagar, Nepal
}

\section{Keywords:}

Gestational diabetes mellitus;

Glucose challenge test; Oral glucose tolerance test; Pregnancy induced hypertension

\begin{abstract}
Background: Gestational diabetes mellitus is defined as any degree of glucose intolerance which is first recognized during pregnancy and is associated with a number of adverse perinatal outcomes, such as neonatal hypoglycemia, macrosomia with an increased risk of shoulder dystocia and the need for neonatal intensive care. Maternal complications include pre-eclampsia and an increased risk of caesarean delivery. The objective of this study was to compare maternal and perinatal outcomes in pregnant women with positive and negative oral glucose tolerance test following positive glucose challenge test.
\end{abstract}

Materials and Methods: This is a prospective observational hospital based study of 120 patients admitted in Nobel Medical College Teaching Hospital, Biratnagar with glucose challenge test positive pregnancy for delivery. Oral glucose tolerance test was performed in all the glucose challenge test positive pregnant and compared with various maternal parameters and newborn's conditions.

Results: Among 120 patients included in the study, 28 (30.4\%) cases were oral glucose tolerance test. Pregnancy induced hypertension was present in 12 cases. Hyperbilirubinemia was present in 42, hypoglycemia in 32, respiratory distress in 44, birth asphyxia in 15 and macrosomia in 6 cases.

Conclusion: Pregnancy induced hypertension and hyperbilirubinemia were found to be significantly higher in OGTT positive cases so early detection of GDM screening via is advisable

\section{Correspondence:}

Dr. Neha Homagai, MBBS,MD

Lecturer, Department of Obstetrics and Gynecology,

Nobel Medical College Teaching Hospital, , Biratnagar, Nepal ORCID ID: 0000-0001-7960-025X

Email-neha_h@hotmail.com

Received : July $17^{\text {th }} 2019$; Accepted : September $5^{\text {th }} 2019$

Citation: Homagai N, Mainali N, Rijal S. Role of positive glucose challenge test only versus oral glucose tolerance test in pregnancy outcome: a comparative study. J Pathol Nep 2019;9:1545-9. DOI:10.3126/jpn.v9i2.25256

Copyright: This is an open-access article distributed under the terms of the Creative Commons Attribution 4.0 International License, which permits unrestricted use, distribution, and reproduction in any medium, provided the original author and source are credited.

\section{INTRODUCTION}

The term diabetes was coined by Aretaeus of Cappadocia. ${ }^{1}$ Gestational diabetes mellitus (GDM) is defined as any degree of glucose intolerance which is first recognized during pregnancy. ${ }^{2}$ This broad definition includes women with undiagnosed type 2 diabetes prior to pregnancy and women who coincidently develop acute type 1 diabetes during pregnancy. The increasing prevalence of type 2 diabetes in general, and in younger people in particular, has led to an increasing number of pregnancies with this complication. ${ }^{2}$ About $10 \%$ of women with GDM have circulating islet-cell antibodies, they may have a "latent" form of type 1 diabetes, although their risk of developing type 1 diabetes is not known. ${ }^{4}$ The increased obstetrical risk 
Table 1: CC Criteria for abnormal result on $100 \mathrm{~g}$ OGTT in pregnant women

\begin{tabular}{lc}
\hline Blood sample & \multicolumn{1}{c}{ CC Criteria } \\
\hline Fasting & $>95 \mathrm{mg} / \mathrm{dL}(5.3 \mathrm{mmol} / \mathrm{L})$ \\
1-hour & $>180 \mathrm{mg} / \mathrm{dL}(10.0 \mathrm{mmol} / \mathrm{L})$ \\
2-hour & $>155 \mathrm{mg} / \mathrm{dL}(8.6 \mathrm{mmol} / \mathrm{L})$ \\
3-hour & $>140 \mathrm{mg} / \mathrm{dL}(7.8 \mathrm{mmol} / \mathrm{L})$
\end{tabular}

associated with GDM was first described by Dr. Hoet JP in 'Diabetes' in 1954. Later, Dr. John B. O'Sullivan published the O'Sullivan criteria, which became the standard for diabetes detection in pregnancy for the next 40 years. ${ }^{5}$

GDM affects between $2 \%$ and $9 \%$ of all pregnant women in Western countries. ${ }^{6-8}$ In India prevalence rate ranges from $15-21 \%{ }^{9}$ In Nepal, the incidence of GDM has been reported as $0.75 \%$ which is quite low. ${ }^{10}$ However, nationwide data is not available.

Hyperglycemia in pregnancy is associated with adverse perinatal outcomes, such as neonatal hypoglycemia, macrosomia, with an increased risk of shoulder dystocia, and need for neonatal intensive care. Maternal complications include an increased risk of pre-eclampsia and caesarean delivery. ${ }^{11}$ Furthermore, women with GDM have up to $60 \%$ risk of developing type- 2 diabetes mellitus within 5-15 years of delivery ${ }^{12,13}$. It has been suggested that children prenatally exposed to a diabetic mother have an increased risk for developing Type 2 diabetes later in life. ${ }^{12-15}$

The American Diabetes Association (ADA) suggests that all the pregnant women between $24^{\text {th }}-28^{\text {th }}$ weeks of gestation should be screened for GDM, unless they are of low risk status. ${ }^{6}$ Universal screening has been endorsed by both the American Diabetes Position Statement and the first, second and third international workshop conferences on GDM. ${ }^{6,16,17}$ The fourth international workshop conference has endorsed on selective screening. It is acknowledged that selective screening approach will miss a proportion of GDM perhaps up to $30 \%{ }^{7}$ The babies of mothers who have diabetes during pregnancy are reported to have $45 \%$ risk of developing diabetes, compared with $8.6 \%$ in babies of mothers who develop diabetes after pregnancy and $1.4 \%$ in babies of mothers without diabetes. ${ }^{18}$

The objective of this research is to study and compare maternal \& perinatal outcomes in pregnant women with positive and negative OGTT following positive GCT.

\section{MATERIALS AND METHODS}

This is a hospital based prospective study done at Nobel medical college hospital and research center, Biratnagar, Nepal from 1st February, 2017 to 31st January, 2018. Ethical clearance was obtained from Institutional Review Committee. During this period, pregnant women of 2428 weeks of gestation attending outpatient department for antenatal checkup were considered for study. GCT was done as a routine test on all of these females, for which $50 \mathrm{gm}$ of glucose dissolved in $200 \mathrm{ml}$ of water, was given to patient to be consumed over 5 minutes period (without regard to time of day or time of last meal). Blood glucose level was measured after one hour of glucose intake. A $\mathrm{GCT} \geq 140 \mathrm{mg} / \mathrm{dL}$ was considered as positive GCT. All patients with positive GCT were included in the study with an exclusion of patients with overt diabetes mellitus and patient with history of pancreatitis. Women with positive GCT were recommended for OGTT. Patient were advised to have unrestricted diet for 3 days prior to the test. The test was performed in the morning after an overnight fast of 8-14hours. Fasting blood glucose sample was taken and then 100 gram of anhydrous glucose was given. Blood glucose level was measured after 1 hour, 2 hours and 3 hours of glucose intake. GDM was diagnosed if two or more of serum glucose values were met or exceeded

Table 2: Distribution of maternal variables among study population.

\begin{tabular}{|c|c|c|c|c|}
\hline Parameter & & OGTT Positive & OGTT Negative & Total \\
\hline \multirow{4}{*}{ Gravida } & Primi & $13(10.83 \%)$ & $40(33.33 \%)$ & $53(44.16 \%)$ \\
\hline & $\mathrm{G} 2$ & $11(9.17 \%)$ & $37(30.83 \%)$ & $48(40.00 \%)$ \\
\hline & G3 & $02(1.67 \%)$ & $09(7.50 \%)$ & $11(9.17 \%)$ \\
\hline & G3 & $02(1.67 \%)$ & $06(5.00 \%)$ & $08(6.67 \%)$ \\
\hline \multirow{3}{*}{ Mode of delivery } & Vaginal & $10(8.34 \%)$ & $52(43.33 \%)$ & $62(51.67 \%)$ \\
\hline & Caesarean section & $14(11.67 \%)$ & $30(25.00 \%)$ & $44(36.67 \%)$ \\
\hline & Vacuum assisted & $04(3.33 \%)$ & $10(8.33 \%)$ & $14(11.66 \%)$ \\
\hline \multirow{3}{*}{ Liquor } & Adequate & $18(15.00 \%)$ & $68(56.67 \%)$ & $86(71.67 \%)$ \\
\hline & Polyhydramnios & $06(5.00 \%)$ & $06(5.00 \%)$ & $12(10.00 \%)$ \\
\hline & Oligohydramnios & $04(3.33 \%)$ & $18(15.00 \%)$ & $22(18.33 \%)$ \\
\hline \multirow{2}{*}{ Pregnancy induced hypertension (PIH) } & Present & $08(6.67 \%)$ & $04(3.33 \%)$ & $12(10.00 \%)$ \\
\hline & Absent & $20(16.67 \%)$ & $88(73.33 \%)$ & $108(90.00 \%)$ \\
\hline \multirow{2}{*}{ Period of gestation } & Preterm & $04(3.33 \%)$ & $20(16.67 \%)$ & $24(20.00 \%)$ \\
\hline & Term & $24(20.00 \%)$ & $72(60.00 \%)$ & $96(80.00 \%)$ \\
\hline
\end{tabular}




\begin{tabular}{|c|c|c|c|c|}
\hline Parameter & & OGTT Positive & OGTT Negative & Total \\
\hline \multirow{2}{*}{ Hypoglycemia } & Present & $08(6.84 \%)$ & $24(20.51 \%)$ & $32(27.35 \%)$ \\
\hline & Absent & $20(17.09 \%)$ & $65(55.56 \%)$ & $85(72.65 \%)$ \\
\hline \multirow{2}{*}{ Birth asphyxia } & Present & $04(3.42 \%)$ & $11(9.40 \%)$ & $15(12.82 \%)$ \\
\hline & Absent & $24(20.51 \%)$ & $78(66.67 \%)$ & $102(87.18 \%)$ \\
\hline \multirow{2}{*}{ Respiratory distress } & Present & $16(13.68 \%)$ & $28(23.93 \%)$ & $44(37.61 \%)$ \\
\hline & Absent & $12(10.25 \%)$ & $61(52.14 \%)$ & $73(62.39 \%)$ \\
\hline \multirow{5}{*}{ Birth weight } & Low birth weight & $06(5.13 \%)$ & $10(8.55 \%)$ & $16(13.68 \%)$ \\
\hline & Appropriate for age & $18(15.38 \%)$ & $77(65.81 \%)$ & $95(81.19 \%)$ \\
\hline & Macrosomia & $04(3.49 \%)$ & $02(1.71 \%)$ & $06(5.13 \%)$ \\
\hline & Hyperbilirubinemia & $22(18.80 \%)$ & $20(17.10 \%)$ & $42(35.90 \%)$ \\
\hline & & $06(5.13 \%)$ & $69(58.97 \%)$ & $75(64.10 \%)$ \\
\hline \multirow{2}{*}{ Period of gestation } & Absent & $20(16.67 \%)$ & $88(73.33 \%)$ & $108(90.00 \%)$ \\
\hline & Preterm & $04(3.33 \%)$ & $20(16.67 \%)$ & $24(20.00 \%)$ \\
\hline
\end{tabular}

according to Carpenter \& Coustan (CC) criteria (Table 1). ${ }^{19}$ All the pregnant women with positive GCT were followed up every four weekly till 28 weeks, every fortnightly till 37 weeks and weekly till delivery. During each antenatal visit weight, blood pressure, symphysio-fundal height, urine sugar, albumin and microscopy, and random blood sugar level of these patients were measured. Patients diagnosed as GDM were also followed up with fasting blood sugar and post prandial blood sugar at each visit. The maternal outcome was followed up in terms of mode of delivery, PIH, status of the liquor and perinatal outcomes was followed up in terms of birth weight, hypoglycemia, macrosomia, hyperbilirubinemia and respiratory distress syndrome.

The data were analyzed using SPSS software and mean, frequency was calculated. Chi-square test was applied to find the p-value where necessary.

\section{RESULTS}

A total of 2357 patients came to OPD for antenatal checkup with a gestational period of 24-28 weeks. GCT was performed on all of these patients. A total of 281(11.9\%) patients with positive GCT were considered for the study and OGTT was done. Out of them, 120 patients who delivered babies in Nobel medical college obstetrics department were taken as the study population. The patient's age ranged from 16 to 39 years. Maternal variables are tabulated in table 2 . Most of the patients were Primi of g2 ( $n=101,: 84.1 \%)$. Pregnancy induced hypertension was observed in $12(10 \%)$ patients (Table 2).Among the total 120 patients with high GCT value, $28(23.34 \%)$ were OGTT positive. Incidence of GDM was $1.18 \%$ in the study population.

Among these variables, PIH showed statistically significant difference between the two groups. and p-value for $\mathrm{PIH}$ was $<0.000183$. Rests of the variables were statistically insignificant.
Among the 120 deliveries, 3 babies died in utero. One had tracheoesophageal fistula. However, the cause of death of other two babies couldn't be identified. Among remaining 117 newborns, hypoglycemia was observed in 32 cases $(27.3 \%)$.

Among these variables, only hyperbilirubinemia show statistically significant difference (p-value $<0.00001)$ between the two groups. Chi-Square test was used to find statistical significance. Rests of the variables were not statistically significant.

\section{DISCUSSION}

GDM is defined as carbohydrate intolerance that is first recognized or begins during pregnancy It is associated with increased maternal, fetal, and neonatal risks. The prevalence of GDM is increasing and it complicates approximately $7 \%$ of all pregnancies in the United States, probably because of increasing rates of overweight and obesity. A universal recommendation for the ideal approach for screening and diagnosis of GDM is difficult to find. At this time, the Committee on Obstetric Practice continues to recommend a two-step approach to screening and diagnosis. ${ }^{20}$

Majority of the cases, among the study population, were delivered vaginally. Out of which 62 cases had spontaneous delivery. Among the OGTT positive cases the numbers of lower segment Caesarean section (LSCS) $(n=14,50 \%)$ outnumbered spontaneous delivery. A major indication for LSCS was failed induction. However, this data was not significant since large number of OGTT negative cases $(n=32,32.6 \%)$ were also delivered by LSCS. Failed induction was the major indication in these cases as well. Deerochanawong et al in their study of 709 women found that $32 \%$ and $70 \%$ of those diagnosed as GDM by World Health Organization (WHO) criteria and National Diabetes Data group (NDDG) criteria respectively underwent LSCS. ${ }^{21}$ 
Emmanuel Odar et al in their study of 90 women, observed that mothers with GDM (WHO criteria) were twice as likely to have caesarean section because of big babies and obstructed labor than the controls without GDM. ${ }^{22}$

In a study by Sahu et al, polyhydramnios was most common antenatal complication and it was observed that $36 \%$ of GDM cases diagnosed by ADA and 22\% GDM cases diagnosed by WHO criteria had polyhydramnios. ${ }^{23}$ In this study, amount of fluid with respect to status of OGTT was not significant.

PIH was the major complication in the patient group with positive OGTT which was statistically significant when compared with negative group. Among the OGTT positive patients $28.57 \%$ showed features of PIH. In a study done by Shrestha et $\mathrm{al}^{16}$ it was $25 \%$ which was comparable with other studies. ${ }^{12,24-26}$ An article published by Wendland et al concluded that there was a positive and statistically significant association between PIH and the WHO diagnostic criteria. ${ }^{27}$

In concordance with other studies, macrosomia was found more in OGTT positive mother. ${ }^{10}$ In study by Schmidt et al, GDM by both WHO and ADA criteria predicted an increased risk of macrosomia, and perinatal death. ${ }^{28}$ Emmanuel Odar et al observed that the babies of mothers with GDM (WHO criteria) were more likely to be macrosomic (36.7\%), perinatal mortality $(16.7 \%)$ and have shoulder dystocia (23.3\%) than those of normal mothers. ${ }^{29}$ A study done at Parkland Hospital, Dallas, risk of malformed infants was $1.5 \%$ in non-diabetic women and this risk was increased 3.2 fold (4.8\%) in women with GDM. ${ }^{30}$ In this study, two babies had congenital anomalies. One out of them died and the one who survived had an atrial septal defect.

Three babies born had died in utero. All of them were born to OGTT negative mothers . Among the alive babies perinatal complications seen were hypoglycemia, hyperbilirubinemia, birth asphyxia and respiratory distress. $78.5 \%$ of babies born from OGTT positive mother developed jaundice. The data was significant statistically and was higher than the other studies. ${ }^{24,30,31}$

\section{CONCLUSIONS}

GCT is a simple, convenient and cheap test and appeared to be a feasible and acceptable screening test. PIH and hyperbilirubinemia showed statistically significant difference between the OGTT positive and negative groups. Hence, OGTT cannot be replaced by GCT for the diagnosis of GDM.

\section{Limitations od study}

- Patients were screened at the OPD and lots of patients were lost in the follow up.

- Some of the patients were delivered outside the Nobel medical college and couldn't be included in the study.

\section{Conflict of Interest: None}

\section{REFERENCES}

1. Lakhtakia R. The history of diabetes mellitus. Sultan Qaboos Univ Med J. 2013 Aug; 13(3): 368-370. Crossref

2. Metzger BE, Coustan DR. Summary and recommendations of the Fourth International Workshop-Conference on Gestational Diabetes Mellitus. The Organizing Committee. Diabetes care. 1998;21 Suppl 2:B161-7

3. Ferrara A, Kahn HS, Quesenberry CP, Riley C, Hedderson MM. An increase in the incidence of gestational diabetes mellitus: Northern California, 1991-2000. Obstetrics and gynecology. 2004;10:526-33. Crossref

4. Ferber K, Keller, E, Albert, ED, Ziegler, AG. Islet cell autoimmunity in women with gestational diabetes and risk of progression to insulindependent diabetes mellitus. Diabetes Metab Rev. 1996;12:275-85. Crossref

5. Knopp RH. John B. O'Sullivan: a pioneer in the study of gestational diabetes. Diabetes care. 2002;25:943-4. Crossref

6. Jensen DM, Damm P, Sorensen B, et al. Proposed diagnostic thresholds for gestational diabetes mellitus according to a 75-g oral glucose tolerance test. Maternal and perinatal outcomes in 3260 Danish women. Diabet Med 2003;20:51-7. Crossref

7. Esakoff TF, Cheng YW, Caughey AB. Screening for gestational diabetes: different cut-offs for different ethnicities? Am J Obstet Gynecol 2005;193:1040-4. Crossref

8. Crowther CA, Hiller JE, Moss JR, McPhee AJ, Jeffries WS, Robinson JS. Effect of treatment of gestational diabetes mellitus on pregnancy outcomes. N Eng1 J Med. 2005;352:2477-86. Crossref

9. V Seshiah VB, Madhuri S Balaji, CB Sanjeevi, A Green. Gestational diabetes mellitus in India. J Assoc Physicians India 2004;52:707-11. Crossref

10. Shrestha A, Chawla CD. The glucose challenge test for screening of gestational diabetes. Kathmandu Univ Med J 2011;9:22-5. Crossref

11. Metzger BE, Lowe LP, Dyer AR, Trimble ER, Chaovarindr U, Coustan DR, et al. Hyperglycemia and adverse pregnancy outcomes. N Engl J Med. 2008;358:1991-2002. $\underline{\text { Crossref }}$

12. Kim C, Newton KM, Knopp RH. Gestational diabetes and the incidence of type 2 diabetes: a systematic review. Diabetes care. 2002;25:1862-8. Crossref

13. O'Sullivan JB. Body weight and subsequent diabetes mellitus. JAMA 1982;248:949-52. Crossref

14. Plagemann A . A matter of insulin: developmental programming of body weight regulation. J Matern Fetal Neonatal Med. 2008;21:1438. Crossref

15. Tam WH, Ma RC, Yang $\mathrm{X}$, et al. Glucose intolerance and cardiometabolic risk in adolescents exposed to maternal gestational diabetes: a 15-year follow-up study. Diabetes care. 2010;33:1382-4. $\underline{\text { Crossref }}$

16. Powers AC. Diabetes Mellitus. 17th ed ed. Fauci AS BE, Kasper DL, Hauser SL, Longo DL, Jameson JL, Loscalzo J. , editor. New York (US): The McGraw-Hill Companies; 2008. 2275 p

17. Freemark M. Regulation of maternal metabolism by pituitary and placental hormones: roles in fetal development and metabolic programming. Horm Res. 2006;65 Suppl 3:41-9. Crossref 
18. Bhattarai MD SD. Learning the lessons - preventing type 2 diabetes in Nepal. Diabetes Voice. 2007; 52.

19. Carpenter MW, Coustan DR. Criteria for screening tests for gestational diabetes.. Am J Obstet Gynecol 1982;144:768-73.

20. Committee opinion no. 504: Screening and diagnosis of gestational diabetes mellitus.. Obstet Gynecol. 2011;118:751-3. Crossref

21. Deerochanawong C, Putiyanun C, Wongsuryrat M, Serirat S, Jinayon P. Comparison of National Diabetes Data Group and World Health Organization criteria for detecting gestational diabetes mellitus. Diabetologia. 1996;39:1070-3. Crossref

22. Odar E, Wandabwa J, Kiondo P. Maternal and fetal outcome of gestational diabetes mellitus in Mulago Hospital, Uganda. Afr. Health Sci.. 2004;4:9-14. Crossref

23. Sahu L SR, Rani R. Comparison of ADA and WHO criteria for Gestational diabetes mellitus and the outcome of pregnancy. Obstet. Med.. 2009;2:149-53. Crossref

24. Lindsay MK, Graves W, Klein L. The relationship of one abnormal glucose tolerance test value and pregnancy complications. Obstet Gynecol. 1989;73(1):103-6. Crossref

25. Joffe GM, Esterlitz JR, Levine RJ, et al. The relationship between abnormal glucose tolerance and hypertensive disorders of pregnancy in healthy nulliparous women. Calcium for Preeclampsia Prevention (CPEP) Study Group. Am J Obstet Gynecol. 1998;179:1032-7. Crossref
26. Innes KE, Wimsatt JH, McDuffie R. Relative glucose tolerance and subsequent development of hypertension in pregnancy. Obstet Gynecol. 2001;97:905-10. $\underline{\text { Crossref }}$

27. Wendland EM, Torloni MR, Falavigna M, et al. Gestational diabetes and pregnancy outcomes--a systematic review of the World Health Organization (WHO) and the International Association of Diabetes in Pregnancy Study Groups (IADPSG) diagnostic criteria. BMC pregnancy and childbirth. 2012;12:23. Crossref

28. Schmidt MI, Duncan BB, Reichelt AJ, et al. Gestational diabetes mellitus diagnosed with a 2-h 75-g oral glucose tolerance test and adverse pregnancy outcomes. Diabetes care. 2001;24:1151-5. $\underline{\text { Crossref }}$

29. McLaughlin GB, Cheng YW, Caughey AB. Women with one elevated 3-hour glucose tolerance test value: are they at risk for adverse perinatal outcomes? Am J Obstet Gynecol. 2006;194:e16-9. Crossref

30. Sheffield JS, Butler-Koster EL, Casey BM, McIntire DD, Leveno KJ. Maternal diabetes mellitus and infant malformations. Obstetrics and gynecology. 2002;100(5 Pt 1):925-30. Crossref

31. Ma KK, Mele L, Landon MB, et al. The obstetric and neonatal implications of a low value on the 50-g glucose screening test. Am J Perinat. 2013;30:715-22. $\underline{\text { Crossref }}$ 